\title{
Treatment of chylothorax developed after congenital heart disease surgery: a case report
}

\author{
Ozgul Bulut, Doruk Gul, Sibel Sevuk, Ilke Mungan, Derya Buyukkayhan \\ Department of Neonatology, Istanbul Medeniyet University Goztepe Training and Research Hospital, Istanbul, Turkey
}

\begin{abstract}
Chylothorax is defined as the accumulation of lymphatic fluid or chyle in the pleural space. Chylothorax treatment is composed of conservative; pleural drainage, termination of enteral feeding, total parenteral nutrition and supplementation with medium- chain triglycerides and surgical therapies; ductus thoracicus ligation, pleuroperitoneal shunts or pleuredesis. Nowadays, for cases among which conservative therapies fail, treatment with octreotide has been reported to be beneficial with promising results. A neonate who developed chylothorax after surgery performed for congenital heart disease was treated successfully with octreotide.
\end{abstract}

Keywords: Chylothorax; congenital heart disease; octreotide; surgery.

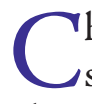
hylothorax which develops following cardiac surgery in pediatric patients is a prevalent complication associated with causes of serious morbidity and mortality including severe malnutrition, impairments in hematological, metabolic and immune systems, need for a longer ventilation and prolongation of hospital stay $[1,2,3]$. In single centered studies incidence of chylothorax following cardiac surgery has been reported as nearly 4-9\% $[3,4,5]$. Development of chylothorax can be associated with injury of the thoracic duct, disruption of lymphatic channels, increase in venous pressure and central venous thrombosis [1].

For the diagnosis of chylothorax pleural fluid should appear like a milk, its culture should be sterile, triglyceride level should be higher than $110 \mathrm{mg} /$ $\mathrm{dL}$, and total amount of cells, and the ratio of lym- phocytes should be above 1000 cells $/ \mu \mathrm{L}$, and $80 \%$, respectively [6].

Current treatment strategies include conservative methods as drainage of the pleural fluid, discontinuation of the enteral nutrition, total parenteral nutrition (TPN), feeding with formulas containing medium chain triglyceride (MCT), and in resistant cases, surgical methods as ligation of the thoracic duct, pleuro-peritoneal shunt or pleurodesis $[6,7]$. However, surgical treatment increases morbidity rates, hospital stay and costs. In the literature, with octreotide treatment successful treatment results have been reported in unresponsive cases [8]. In this case report we presented a patient who had chylothorax developed after surgical procedure because of congenital heart disease in the neonatal period.

Received: September 08, 2015 Accepted: November 02, 2015 Online: December 25, 2015

Correspondence: Dr. Ozgul BULUT. Istanbul Medeniyet Universitesi Goztepe Egitim ve Arastirma Hastanesi, Neonatoloji Bilim Dali, Istanbul, Turkey. 


\section{CASE REPORT}

A male baby was born via cesarean section at 38 $1 / 7$ weeks gestation and birth weight of $2970 \mathrm{~g}$. On antenatal ultrasound (US) atrioventricular septal defect was detected. On physical examination, the patient with respiratory distress was intubated and hospitalized in the neonatal intensive care unit. On echocardiograms complete atrioventricular channel defect, muscular ventricular septal defect and pulmonary hypertension were detected. Diuretic and inotropic treatment were initiated. Transfontanel and abdominal US findings were unremarkable. Pulmonary artery band operation was performed the postnatal $40^{\text {th }}$ day. Twenty days after the procedure, the patient was extubated and monitored with continuous positive airway pressure (CPAP). During monitorization, respiratory distress increased progressively and he was re-intubated. On physical examination, decreased respiratory sounds on the left hemithorax were auscultated. On telecardiogram left lung was opaque and consistent with pleural effusion (Figure 1). Pleural fluid was detected $4 \mathrm{~cm}$ on thoracic US. For diagnosis and treatment $50 \mathrm{ml}$ milky-colored fluid was evacuated with thoracentesis (Figure 2). Biochemical analysis of the sample fluid was determined as follows: triglyceride, $161 \mathrm{mg} / \mathrm{dL}, \mathrm{WBC} 1300 / \mathrm{mm}^{3}$ with a $90 \%$ lymphocyte dominancy and culture negativity. One day later $50 \mathrm{ml}$ fluid was drained, baby formulas containing TPN and MCT were initiated. Series pulmonary chest radiograms revealed persistence of preexisting pleural effusion, consequently, a chest tube was implanted into the left hemithorax and underwater drainage was performed. On the third day of the treatment her respiratory distress persisted, and amount of pleural fluid did not change which encouraged us to initiate three equal doses of octreotide $\left(10 \mu \mathrm{g} / \mathrm{kg} / \mathrm{d} / \mathrm{SC}\right.$ Sandostatin $\left.{ }^{\circ}\right)$. On the eight day of the treatment, intravenous infusion treatment with octreotide doses of $3 \mu \mathrm{g} / \mathrm{kg} / \mathrm{h}$ was initiated. The dose of octreotide was increased stepwise. On the 20th day of the treatment amount of the drained fluid decreased. Control pulmonary radiogram was normal and thoracic US did not reveal any pleural effusion. (Figure 3). Chest tube was removed. The patient was extubated because of regression of respiratory failure symptoms and he was monitored on nasal CPAP support. Any adverse

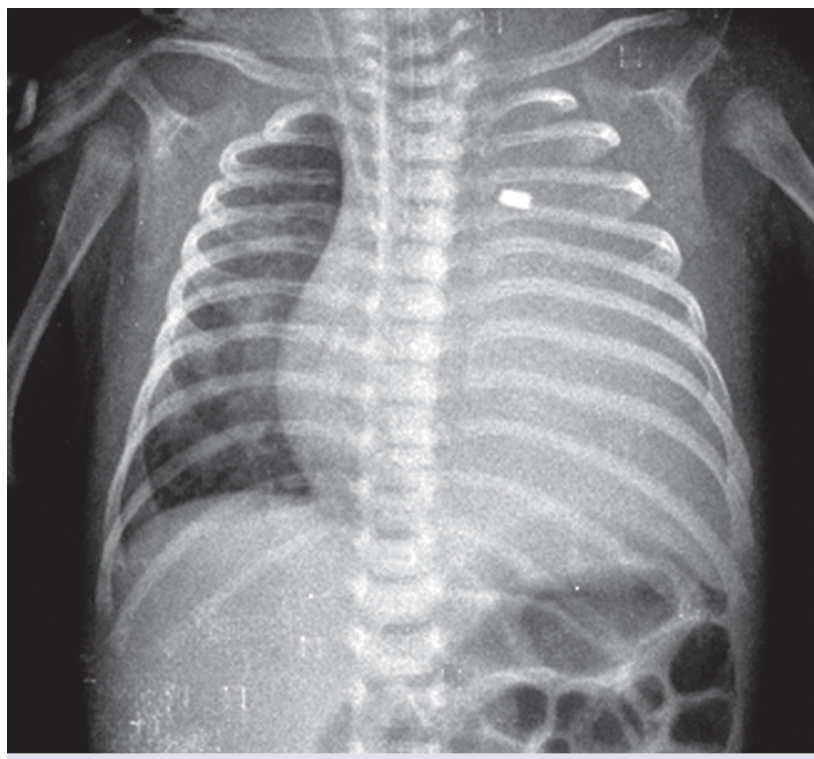

FIGURE 1. On telecardiogram opacified left lung consistent with pleural effusion.

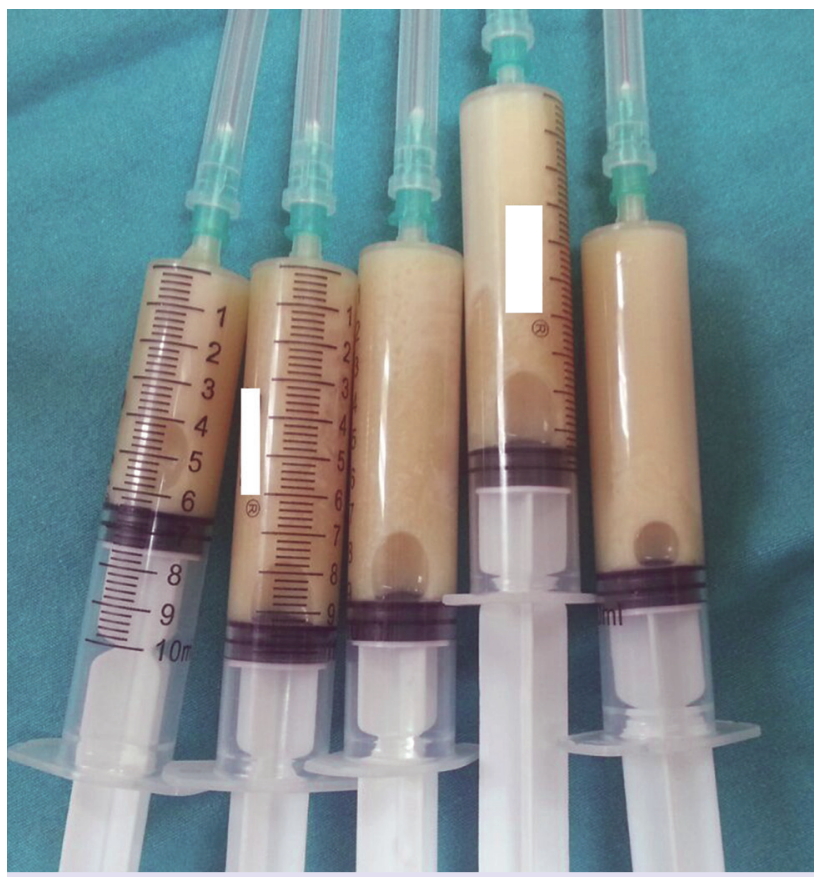

FIGURE 2. Milky colored pleural fluid drawn by thoracentesis.

effect secondary to octreotide treatment was not seen. The dose of octerotide was tapered and finally discontinued. The baby was gradually switched to breast feeding. Parents of our case gave their "Informed Consent" for the publication of this case 


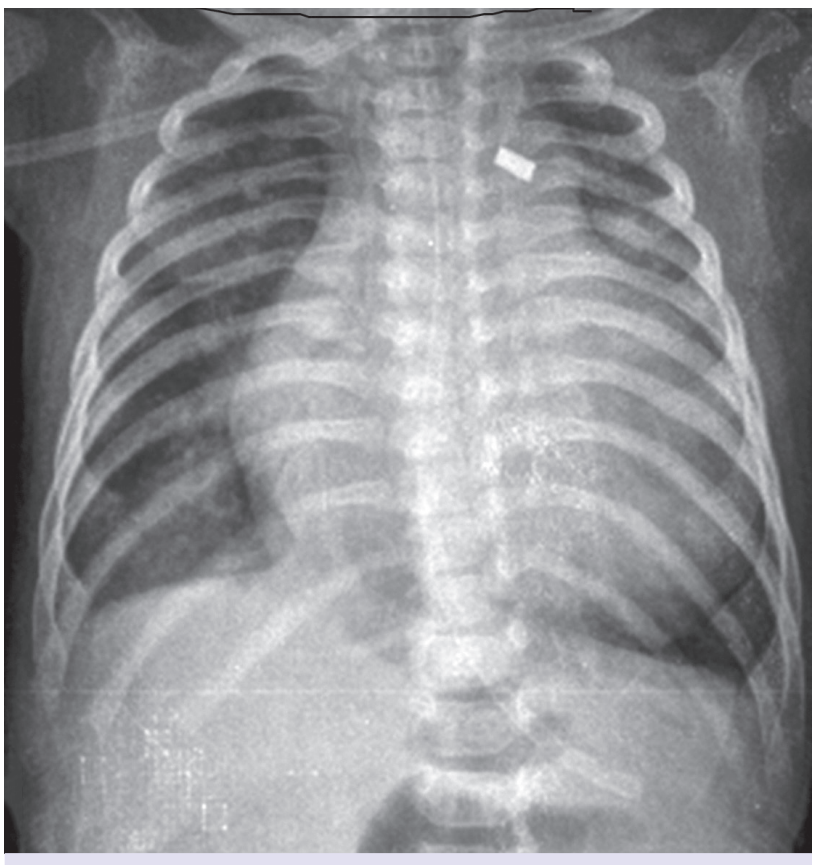

FIGURE 3. Post-treatment control telecardiogram.

report.

\section{DISCUSSION}

Chylothorax which develops following cardiac surgery in pediatric patients is a prevalent complication associated with causes of serious morbidity and mortality. However, a complete consensus does not exist about the optimal treatment approach for chylothorax developed after surgery. In the literature, various algorithms have been developed dependent on the experience and preferences of the physicians $[3,4,9]$. Generally, preferred method is conservative approach including discontinuation of enteral nutrition, feeding with formula containing TPN or MCT, drainage of pleural fluid and mechanical ventilation. This treatment leads to hypoproteinemia, coagulopathy, lymphopenia, hypogammaglobulinemia, sepsis and ventilation-related pulmonary injury [10]. Firstly, in the year 1998, in the medical treatment of chyhlothorax developed following cardiac surgery the use of intravenous somotastatin was reported [11].

Octreotide is a long-acting synthetic somatostatin analogue. Though mechanism of action of somatostatin and octreotide has not been fully elu- cidated, its suppressive effects on lymphatic fluid formation predominantly by vasoconstriction and resultant decrease in splenic blood flow $[12,13]$. Somatostatin is administered as a continuous infusion, while octreotide can be also applied as subcutaneous injection. Recommended initial dose of somatostatin can be as high as $3.5 \mathrm{mg} / \mathrm{kg} / \mathrm{h}$, while in case of need use octreotide dose within the range of $0.3-10 \mu \mathrm{g} / \mathrm{kg} / \mathrm{hr}$ is recommended [14, 15]. Optimal timing and dose of these two drugs have not been known so far [12]. Though duration of treatment is controversial, generally treatment should be continued for 3-5 days after cessation of the drainage of the pleural fluid $[8,16]$. During treatment with octreotide and somotatin adverse effects as hyperglycemia, hypothyroidism, muscle cramps, hypertension, nausea, diarrhea, necrotizing enterocolitis, renal involvement and hepatic dysfunction can be encountered [17]. Development of anaphylaxis secondary to octreotide use has been reported [18].

In the treatment of chylothorax which develops during childhood where conservative and medical treatment modalities failed, surgical treatment alternatives should be conceived. Thoracic duct ligation described by Lampson in 1948 is used prevalently in patients who did not recover with medical treatment [19]. Obliteration of pleural space with surgical or chemical methods is another surgical method. To this end, tetracyclin, talc, bleomycin, and povidone iodure have been used [17]. In cases where lymph leakage continues despite medical, and surgical treatment modalities, pleuroperitoneal shunt can be applied [12].

In this case, intravenous octreotide was used in the treatment of chylothorax developed following cardiac surgery during neonatal period with successful outcomes. We hope that this treatment modality will take its proper place in routine clinical use after prospective controlled studies.

Conflict of Interest: No conflict of interest was declared by the authors.

Financial Disclosure: The authors declared that this study has received no financial support.

\section{REFERENCES}

1. Zuluaga MT. Chylothorax after surgery for congenital heart dis- 
ease. Curr Opin Pediatr 2012;24:291-4.

2. McCulloch MA, Conaway MR, Haizlip JA, Buck ML, Bovbjerg VE, Hoke TR. Postoperative chylothorax development is associated with increased incidence and risk profile for central venous thromboses. Pediatr Cardiol 2008;29:556-61.

3. Chan EH, Russell JL, Williams WG, Van Arsdell GS, Coles JG, McCrindle BW. Postoperative chylothorax after cardiothoracic surgery in children. Ann Thorac Surg 2005;80:1864-70.

4. Biewer ES, Zürn C, Arnold R, Glöckler M, Schulte-Mönting J, Schlensak C, et al. Chylothorax after surgery on congenital heart disease in newborns and infants -risk factors and efficacy of MCT-diet. J Cardiothorac Surg 2010;5:127.

5. Cormack BE, Wilson NJ, Finucane K, West TM. Use of Monogen for pediatric postoperative chylothorax. Ann Thorac Surg 2004;77:301-5.

6. Paramés F, Freitas I, Fragata J, Trigo C, Pinto MF. Octreotide-additional conservative therapy for postoperative chylothorax in congenital heart disease. Rev Port Cardiol 2009;28:799-807.

7. Migliori C, Boroni G, Milianti S, Ekema G. Chylothorax. [Article in Italian] Minerva Pediatr 2010;62(3 Suppl 1):89-91. [Abstract]

8. Das A, Shah PS. Octreotide for the treatment of chylothorax in neonates. Cochrane Database Syst Rev 2010;9:CD006388.

9. Panthongviriyakul C, Bines JE. Post-operative chylothorax in children: an evidence-based management algorithm. J Paediatr Child Health 2008;44:716-21.

10. Au M, Weber TR, Fleming RE. Successful use of somatostatin in a case of neonatal chylothorax. J Pediatr Surg 2003;38:1106-7.

11. Rimensberger PC, Müller-Schenker B, Kalangos A, Beghetti M. Treatment of a persistent postoperative chylothorax with somatostatin. Ann Thorac Surg 1998;66:253-4.

12. Soto-Martinez M, Massie J. Chylothorax: diagnosis and management in children. Paediatr Respir Rev 2009;10:199-207.

13. Kalomenidis I. Octreotide and chylothorax. Curr Opin Pulm Med 2006;12:264-7.

14. Goto M, Kawamata K, Kitano M, Watanabe K, Chiba Y. Treatment of chylothorax in a premature infant using somatostatin. J Perinatol 2003;23:563-4.

15. Helin RD, Angeles ST, Bhat R. Octreotide therapy for chylothorax in infants and children: A brief review. Pediatr Crit Care Med 2006; 7:576-9.

16. Moreira-Pinto J, Rocha P, Osório A, Bonet B, Carvalho F, Duarte $\mathrm{C}$, et al. Octreotide in the treatment of neonatal postoperative chylothorax: report of three cases and literature review. Pediatr Surg Int 2011;27:805-9.

17. Tutor JD. Chylothorax in infants and children. Pediatrics 2014;133:722-33.

18. Azkur D, Yoldas T, Toyran M, Kocabas CN. A pediatric case of anaphylaxis due to octreotide. Asian Pac J Allergy Immunol 2011;29:361-3.

19. Zanin A, Padalino MA, Cerutti A, Vida VL, Milanesi O, Stellin $\mathrm{G}$, et al. Surgical ligation of cisterna chyli: an alternative treatment for chronic chylothorax in children. Ann Thorac Surg 2010;90:1732-4. 